\title{
Pivotal Roles of Metal Oxides in the Formation of Environmentally Persistent Free Radicals
}

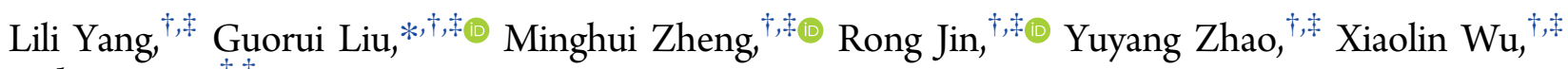 \\ and Yang $\mathrm{Xu}^{\dagger, \dagger}$
}

${ }^{\dagger}$ State Key Laboratory of Environmental Chemistry and Ecotoxicology, Research Center for Eco-Environmental Sciences, Chinese
Academy of Sciences, P.O. Box 2871, Beijing 100085, China ${ }^{\ddagger}$ University of Chinese Academy of Sciences, Beijing 100049, China

\section{Supporting Information}

ABSTRACT: Environmentally persistent free radicals (EPFRs) are emerging pollutants that can adversely affect human health. Although the pivotal roles of metal oxides in EPFR formation have been identified, few studies have investigated the influence of the metal oxide species, size, or concentration on the formation of EPFRs. In this study, EPFR formation from a polyaromatic hydrocarbon with chlorine and hydroxyl substituents (2,4-dichloro-1-naphthol) was investigated using electron paramagnetic resonance spectroscopy. The effect of the metal oxide on the EPFR species and its lifetime and yield were evaluated. The spectra obtained with catalysis by $\mathrm{CuO}, \mathrm{Al}_{2} \mathrm{O}_{3}, \mathrm{ZnO}$, and $\mathrm{NiO}$ were obviously different, indicating that different EPFRs formed. The abilities of the metal oxides to promote EPFR formation were in the order $\mathrm{Al}_{2} \mathrm{O}_{3}>$ $\mathrm{ZnO}>\mathrm{CuO}>\mathrm{NiO}$, which were in accordance with the oxidizing strengths of the metal cations. A decay study showed that the generated radicals were

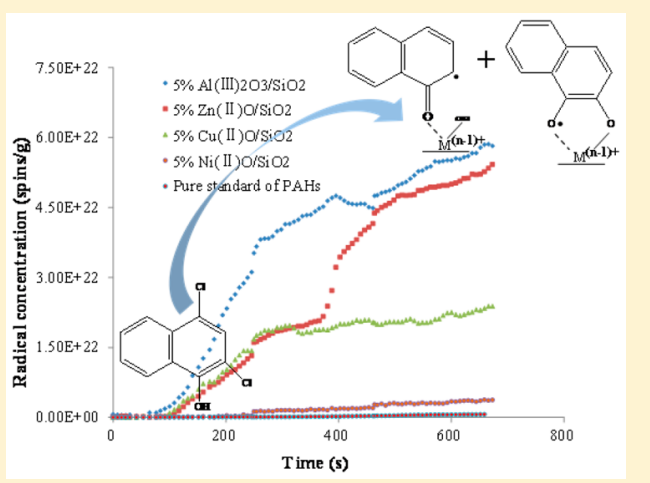
persistent, with a maximum $1 / e$ lifetime of 108 days on the surface of $\mathrm{Al}_{2} \mathrm{O}_{3}$. The radical yields were dependent on the concentration and particle size of the metal oxide. Metal oxide nanoparticles increased the EPFR concentrations more than micrometer-sized particles.

\section{INTRODUCTION}

Environmentally persistent free radicals (EPFRs), which are emerging surface-stabilized pollutants, ${ }^{1}$ are formed and stabilized by the interactions of metal oxides with aromatic compounds via surface-mediated processes. ${ }^{2-4}$ Thermal processes such as waste incineration and various metal smelting process produce abundant aromatic hydrocarbons, ultrafine particles, and transition metal oxides, which can easily generate EPFRs in the cooling zone of a waste incinerator or smelter. ${ }^{5}$ Because cooling zones are essential in thermal processes, EPFR formation can occur in these processes, and once generated, these species will not be destroyed because of the relatively low temperature in the cooling zone. The effects of EPFRs on the environment and human health were highlighted recently. ${ }^{6,7}$ Exposure to fine particles containing EPFRs emitted from thermal processes to the atmosphere can negatively affect human health by inducing generation of harmful reactive oxygen species and DNA damage. ${ }^{8,9}$ Further studies on the mechanisms and factors that influence EPFR formation are essential for their effective control in the environment.

EPFRs can be formed by electron transfer from a substituted aromatic compound to a metal cation center. ${ }^{10}$ Fine particles of copper-EPFR complexes are stable and do not react rapidly with air, which means they can be transported over long distances in the environment and eventually participate in atmospheric reactions. ${ }^{11}$ Previous studies have demonstrated that ferric oxides and copper oxides $(\mathrm{CuO})$ may act as important surface catalysts for EPFR formation. However, the EPFR species that form on $\mathrm{CuO}$ and $\mathrm{Fe}_{2} \mathrm{O}_{3}$ are different and have different lifetimes, with chlorinated EPFRs forming on copper-containing particles and nonchlorinated EPFRs forming on iron-containing particles. ${ }^{11}$ The observation of different EPFR species, lifetimes, and yields with these metal oxides suggests that other metal oxides should be studied as potential sources of EPFR-containing particles. In addition, in different thermal processes, such as secondary metal smelting, iron ore sintering plants, and waste incineration, metal oxide concentrations can vary widely. ${ }^{12-14}$ Because of the widespread distribution of metal oxides in thermal processes, it is of interest to evaluate how the concentrations of metal oxides affect the EPFR yields and species. Furthermore, the concentrations of metal oxides in particulate matter (PM) may affect the metal oxide cluster size, ${ }^{15}$ which is important in determining the catalytic activity because it affects the surface energy and can affect the chemical behaviors of the EPFRs formed. ${ }^{16}$ EPFRs attach more easily to fine particles than coarse particles because fine particles have large surface areas and porous surfaces. ${ }^{17}$ To date, even though it has been reported that

\section{Received: July 14, 2017}

Revised: September 21, 2017

Accepted: October 13, 2017

Published: October 13, 2017 
nanoparticles are largely retained on solid waste combustion residues in full-scale incinerators and in metal smelting processes, ${ }^{18-20}$ the effect of metal oxide particle size on EPFR formation has not been evaluated. Nanoparticles of various oxides are ubiquitous in the atmosphere because of their widespread use in various applications, such as electronic devices, cosmetics, food additives, and medicine. ${ }^{21}$ Nanoparticles containing organic pollutants such as EPFRs may exist long term in the atmosphere, and when they finally settle, it is into sediments, water, and organisms. ${ }^{19,22}$ Reportedly, $80 \%$ of the nanoparticles produced annually are silica $\left(\mathrm{SiO}_{2}\right)$, alumina $\left(\mathrm{Al}_{2} \mathrm{O}_{3}\right)$, and titanium dioxide particles, and the remaining $20 \%$ are oxides of other metals, including zinc, copper, nickel, iron, and certain rare elements. ${ }^{23}$ Estimated annual production of silica $\left(\mathrm{SiO}_{2}\right)$ nanoparticles exceeds 25000 tons, and estimated annual production is 2000 tons for zinc oxide and 3000 tons for oxides of nickel, copper, alumina, iron, and titanium. ${ }^{23}$ Metal oxide nanoparticles are an environmental risk and toxic to organisms through mechanisms mediated by both reactive oxygen species and other species. ${ }^{24,25}$ Even though the direct effects of nanoparticles on human health have been investigated recently, ${ }^{26-28}$ their indirect effects on the environment and the formation of organic pollutants (e.g., by catalysis) have not been evaluated. Therefore, in consideration of the magnitude of nanoparticle output and possible synergy between metal oxide nanoparticles and EPFRs in toxicity, the effect of metal oxide particle size, and especially nanoparticles, on EPFR formation should also be evaluated.

Although substituted phenols and benzenes have been studied extensively, ${ }^{2,4,11,29}$ chlorine- and hydroxyl-substituted polyaromatic hydrocarbons (PAHs) could also be transformed on metal oxide surfaces during thermal processes. ${ }^{30,31}$ PAHs such as pyrene, phenanthrene, and naphthalene have delocalized $\pi$ electrons that can bond with complexed metal ions, which results in electron transfer from the aromatic compound to surface cations. $^{32}$ As a result, free radicals are easily generated by interactions between metal oxide particles and PAHs. However, most studies on EPFR formation have used chlorophenol as a precursor, $^{11,33}$ and few studies have looked at formation of free radicals from PAHs and the persistence of these radicals on metal oxide particles.

In this study, we investigated formation of EPFRs from a chlorine- and hydroxyl-substituted PAH (2,4-dichloro-1-naphthol) in thermochemical reactions $(298-573 \mathrm{~K})$ under the catalysis of metal oxide-containing $\mathrm{SiO}_{2}$ particles. The catalytic effects of different metal oxides on the EPFR species, lifetimes, and yields were assessed to evaluate the potential sources of EPFR-containing particles. In addition, the effects of the concentrations and cluster sizes of the metal oxides on the catalytic activity were estimated. Formation of EPFRs from the $\mathrm{PAH}$ during the thermochemical reactions was monitored by electron paramagnetic resonance (EPR) spectroscopy. The intermediates detected by EPR and the differences observed for catalysis by the different metal oxides were used to explore possible mechanisms for EPFR formation from PAHs.

\section{MATERIALS AND METHODS}

In Situ Detection of Free Radicals Involved in the Thermochemical Reactions of a PAH by EPR Spectroscopy. In situ detection of free radicals formed during the thermochemical reactions of PAH derivatives was conducted by inserting a dewar into the cavity of the EPR spectrometer. The first step in the heating process was heating of nitrogen by the heater strip in the dewar. The nitrogen was contained in a nitrogen line that was interfaced with the dewar. Then the hot nitrogen gas was used to heat the samples in the EPR tube. This process ensured that the tube was heated isothermally. Dynamic changes in the radicals during the heating process were monitored by continuous spectral scanning under the same operating parameters. Chemicals (with purities > 99.9\%), including $\mathrm{CuO}, \mathrm{Al}_{2} \mathrm{O}_{3}$, zinc oxide $(\mathrm{ZnO})$, and nickel oxide $(\mathrm{NiO})$, were purchased from Aladdin Industrial Corp. (Shanghai, China). 2,4-Dichloro-1-naphthol (purity 99\%) was purchased from Alfa Aesar China (Shanghai, China). Metal oxides of different sizes ( $\varnothing 5 \mu \mathrm{m}$ or $ø 30 \mathrm{~nm}$ ) were compared in this study. $\mathrm{SiO}_{2}$ was used as an inert substrate to facilitate control of the metal oxide mass fraction and sample handling. ${ }^{5}$ The $\mathrm{SiO}_{2}$ particles had a diameter of $10 \mathrm{~nm}$ (Sigma-Aldrich, Co., St. Louis, MO), $25 \mu \mathrm{m}$, or $100 \mu \mathrm{m}$ (Sinopharm Chemical Reagent Co., Beijing, China). Before use, the $\mathrm{SiO}_{2}$ particles were heated at $723 \mathrm{~K}$ for $4 \mathrm{~h}$ to remove potential organic contaminants. The effect of the $\mathrm{CuO}$ mass fraction on EPFR formation was investigated by altering the mass fraction $(0.5 \%, 1 \%, 5 \%, 10 \%$, or $15 \%)$ of $\mathrm{CuO}$ in the $\mathrm{SiO}_{2}$ particles. Experiments were conducted by loading either 2,4-dichloro-1-naphthol or a mixture of 2,4dichloro-1-naphthol and metal oxide $/ \mathrm{SiO}_{2}$ into the EPR quartz tube (internal diameter $=4 \mathrm{~mm}$, length $=10 \mathrm{~cm}$ ) to a height of 1 $\mathrm{cm}$. Thermal chemical reactions were conducted at temperatures ranging from 298 to $573 \mathrm{~K}$. The quartz tube was heated by an electric wire in the dewar under atmospheric pressure. After heating, the samples were cooled to $298 \mathrm{~K}$ and periodically analyzed by EPR to study decay of any EPFRs formed during the thermal process. All EPR spectra were recorded on a Bruker EMX-plus X-band EPR spectrometer (Bruker Instruments, Billerica, MA). The instrument and operating parameters were as follows: center field, $3500 \mathrm{G}$; microwave frequency, $9.84 \mathrm{GHz}$; microwave power, $0.63 \mathrm{~mW}$; modulation frequency, $100 \mathrm{kHz}$; modulation amplitude, $1.0 \mathrm{G}$; sweep width, $200 \mathrm{G}$; receiver gain, $30 \mathrm{~dB}$; and time constant, $0.01 \mathrm{~ms}$. Radical quantification was conducted using Bruker's Xenon program according to the quantitative theory of spin calculation. ${ }^{4}$ The details for the quantitation are given in our previous study. ${ }^{4}$ Blank experiments with metal oxide $/ \mathrm{SiO}_{2}$ without the $\mathrm{PAH}$ were performed along with each batch of samples to confirm that no EPFRs formed during the thermal process without the precursor.

Method for Evaluating the Lifetimes of EPFRs Formed with Metal Oxide Catalysis. Kinetic studies were conducted to determine the persistence of EPFRs derived from PAHs under catalysis by different metal oxide particles. Solid samples were exposed to ambient air and stored in a controlled temperature and humidity incubator. The samples were periodically analyzed by EPR. The $1 / e$ lifetimes $\left(t_{1 / e}\right)$ of the EPFRs were evaluated according to the pseudo-first-order integrated rate law expression as follows ${ }^{31,32}$

$$
\begin{aligned}
& \ln \left(C / C_{0}\right)=-k t \\
& t_{1 / e}=1 / k
\end{aligned}
$$

where $k$ is the rate constant, derived from the slope of the logarithm of the radical concentration ratio $\left(C / C_{0}\right)$ versus time $(t)$.

\section{RESULTS AND DISCUSSION}

EPFR Formation under Catalysis by Different Metal Oxides Loaded on $\mathrm{SiO}_{2}$ Particles. Different metal oxides loaded on $\mathrm{SiO}_{2}$ particles were used as the reaction substrate to 

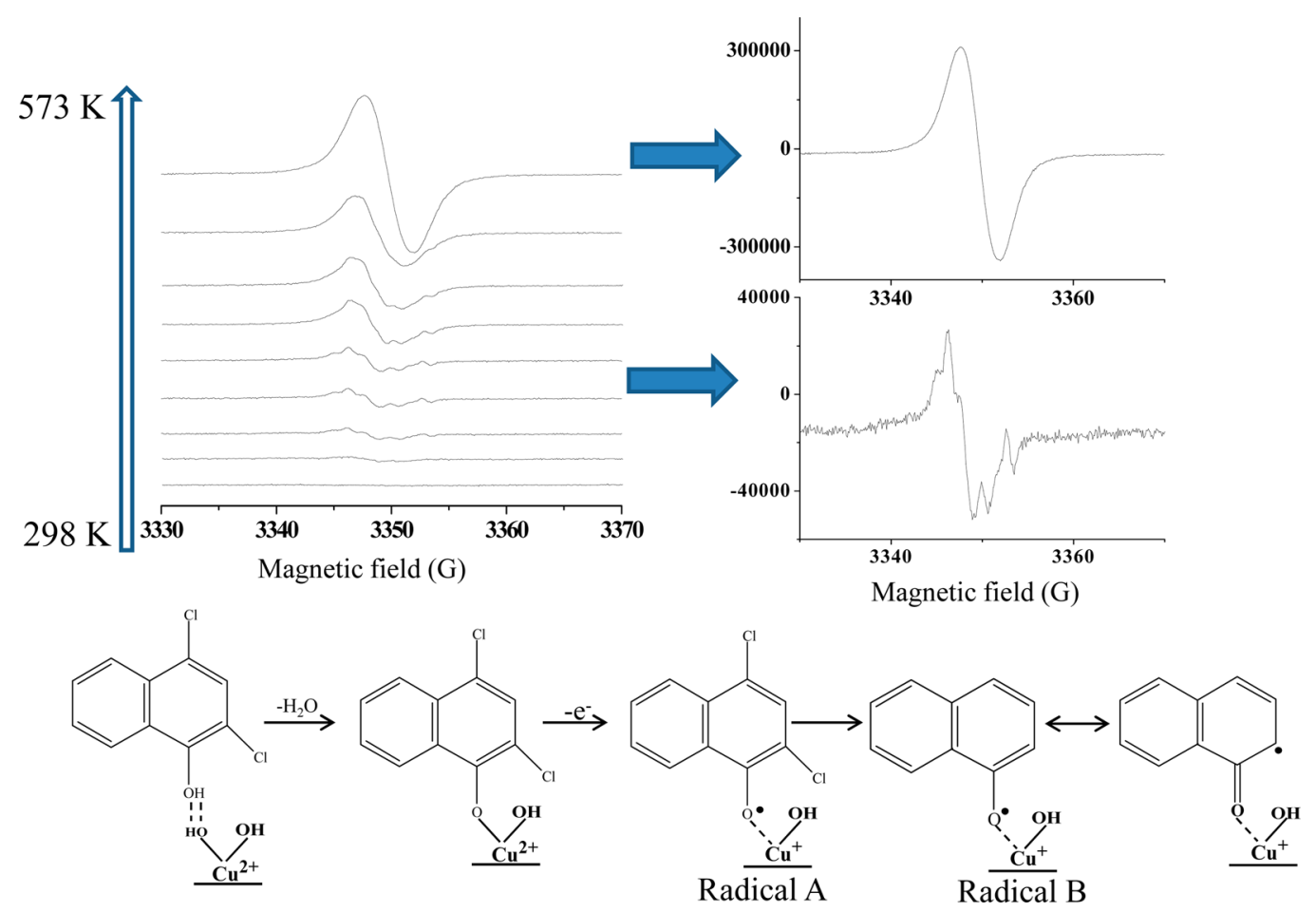

Figure 1. Dynamic changes in the electron paramagnetic resonance spectra of 2,4-dichloro-1-naphthol on the surface of silica-supported CuO from 298 to $573 \mathrm{~K}$.

Table 1. Electron Paramagnetic Resonance (EPR) Spectral Characteristics of Environmentally Persistent Free Radicals (EPFRs) Produced from 2,4-Dichloro-1-naphthol on Different Metal Oxide-Containing Particles at $573 \mathrm{~K}$

\begin{tabular}{|c|c|c|c|c|c|}
\hline Substrates & \multicolumn{2}{|c|}{ g values } & $\begin{array}{c}\Delta \mathrm{Hp}-\mathrm{p} \\
\text { (Gauss) }\end{array}$ & $\begin{array}{c}\text { EPR spectrum at } \\
350 \mathrm{~K}\end{array}$ & $\begin{array}{l}\text { EPFR concentration } \\
\text { (spins/g) at } 598 \mathrm{~K}\end{array}$ \\
\hline $\begin{array}{c}\text { Pure } \\
\text { standard }\end{array}$ & \multicolumn{2}{|c|}{2.0032} & 3.58 & & $6.5 \times 10^{20}$ \\
\hline $\mathrm{CuO}$ & \multicolumn{2}{|c|}{2.0034} & 4.1697 & & $2.38 \times 10^{22}$ \\
\hline \multirow{2}{*}{$\mathrm{Al}_{2} \mathrm{O}_{3}$} & g1 & 2.0036 & 3.96 & & \multirow{2}{*}{$5.82 \times 10^{22}$} \\
\hline & $\mathrm{g} 2$ & 2.0063 & 4.13 & 2.0036 & \\
\hline \multirow[t]{2}{*}{$\mathrm{ZnO}$} & g1 & 2.0029 & 4.96 & & \multirow{2}{*}{$5.42 \times 10^{22}$} \\
\hline & g2 & 2.0039 & 4.52 & 2.0035 & \\
\hline \multirow[t]{2}{*}{$\mathrm{NiO}$} & g1 & 2.0029 & 3.47 & 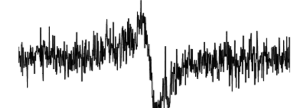 & \multirow[t]{2}{*}{$3.72 \times 10^{21}$} \\
\hline & g2 & 2.0039 & 3.16 & $\frac{M}{2.0035}$ & \\
\hline
\end{tabular}

simulate EPFR formation during thermal processes. A general mechanism for EPFR formation under the catalysis of metal oxides has been proposed and is widely recognized. ${ }^{5,10,11,34}$ In the present study, this mechanism was adapted to the formation of EPFRs with 2,4-dichloro-1-naphthol as the precursor. The precursor first adsorbed onto the metal oxide surface by physical 
adsorption and was then chemisorbed by elimination of $\mathrm{H}_{2} \mathrm{O}$ / $\mathrm{HCl}$, which resulted in surface-bound EPFRs. Simultaneous electron transfer to the metal cation center occurred. Transformation between oxygen- and carbon-centered radicals might occur (Figure S1). To further investigate the differences among EPFRs produced on various metal oxides, 2,4-dichloro-1naphthol was mixed thoroughly with $\mathrm{SiO}_{2}$ particles containing $\mathrm{CuO}, \mathrm{Al}_{2} \mathrm{O}_{3}, \mathrm{ZnO}$, or $\mathrm{NiO}$ ( $5 \%$ mass fraction) and used for in situ EPR experiments. Adsorption of 2,4-dichloro-1-naphthol on the surfaces of different metal oxide particles resulted in formation of surface species with distinct paramagnetic signals (Figures 1 and S2). Even though the same adsorbates were used, the differences in reactivity of the different metal oxide surfaces resulted in formation of different EPFRs. None of the 2,4-dichloro-1naphthol and metal oxide $/ \mathrm{SiO}_{2}$ mixtures generated free radicals at room temperature. Figure 1 shows the dynamic changes in free radical formation in the system when the temperature was increased from 298 to $573 \mathrm{~K}$. At around $350 \mathrm{~K}$, radical A could be formed under the catalysis of $\mathrm{CuO} / \mathrm{SiO}_{2}$, according to the hyperfine signals during the thermal process. The hyperfine signals indicated the existence of interaction of two chlorine nuclear spins and one electron spin, ${ }^{4}$ which indicated the energetically favorable tendency of elimination of $\mathrm{H}_{2} \mathrm{O}$ over $\mathrm{HCl}$. When the temperature increased, dechlorination of radical $\mathrm{A}$ occurred to form radical $\mathrm{B}$ at a temperature $(573 \mathrm{~K})$ that provided sufficient thermal energy to overcome the activation barrier to eliminate both $\mathrm{H}_{2} \mathrm{O}$ and $\mathrm{HCl}$. The EPR signals of radical formed at the temperature of $573 \mathrm{~K}$, which had a narrow line width $\left(\Delta H_{\mathrm{p}-\mathrm{p}}\right)$ of $4.17 \mathrm{G}$, were monitored at different microwave attenuations in this study. The results showed that the EPR signals were quite stable with only slight changes in the signal intensities and line widths with changes in the microwave power. This indicated that signals at the temperature of $573 \mathrm{~K}$ was pure and represented one type of radical (Figure S3). The formation pathways of radicals A and B were consistent with our previous study of trichlorophenol-induced radical formation on the surfaces of $\mathrm{CuO}$ particles. ${ }^{4}$ The formation mechanism of EPFRs can also be demonstrated by the valence change of copper ion. The detection of $\mathrm{Cu}(\mathrm{I})$ in the reaction system after the thermal process indicated the reduction of $\mathrm{Cu}(\mathrm{II})$ and the electron transfer (cf. Figure S4).

Nevertheless, obvious changes were observed in the EPR signal when the catalyst was changed from $\mathrm{CuO}$ to another metal oxide, such as $\mathrm{Al}_{2} \mathrm{O}_{3}, \mathrm{ZnO}$, or $\mathrm{NiO}$. Similar EPR spectra with a single, unstructured signal were obtained for the adsorption of 2,4-dichloro-1-naphthol on $\mathrm{SiO}_{2}$ particles containing $5 \% \mathrm{Al}_{2} \mathrm{O}_{3}$, $\mathrm{ZnO}$, and $\mathrm{NiO}$ at $298-573 \mathrm{~K}$ (Figure S1). The EPR spectral profiles were asymmetrical, indicating the presence of more than one type of EPFR. Simulation of the EPR spectra resulted in the identification of at least two different spectral components with $g$ factors between 2.0029 and 2.0063 (Table 1), which were typical of those for surface-adsorbed aromatic radicals. ${ }^{5,34}$ The $g$ factors of the radicals on the $\mathrm{Al}_{2} \mathrm{O}_{3}$ particles were higher than those of the $\mathrm{ZnO}$ and $\mathrm{NiO}$ particles, indicating more oxygen-centered radicals formed or chlorine atoms existed near the radicals with catalysis by $\mathrm{Al}_{2} \mathrm{O}_{3}$. A semiquinone-type radical with a chlorine atom nearby (radical $\mathrm{C}$ in Figure S2) could also exist with catalysis by $\mathrm{Al}_{2} \mathrm{O}_{3}$ particles with a $g$ factor of 2.0063 observed, suggesting both $\mathrm{H}_{2} \mathrm{O}$ and $\mathrm{HCl}$ elimination by chlorine and hydroxyl substituents in reaction with the surface. A single-line EPR spectrum was recorded under the catalysis of $\mathrm{ZnO}$ and $\mathrm{NiO}$ particles, with $g$ factors of at least two radical kinds of $g 1$ (2.0029) and $g 2$ (2.0039) after deconvolution. These were characterized as oxygen-centered and carbon-centered radicals or carboncentered radicals with an adjacent oxygen atom ( $g$ factor 2.003-2.004) (Figure S2). ${ }^{2}$ In addition, the shapes of the EPR spectra and the relative intensities of the $g 1$ and $g 2$ signals varied with the adsorption temperature. When the temperature increased, more free radicals were generated and $\Delta H_{\mathrm{p}-\mathrm{p}}$ broadened slightly from 3.2 to $5.0 \mathrm{G}$. The ratio of $g 1$ to $g 2$ was close to one on both the $\mathrm{ZnO}$ and the $\mathrm{NiO}$ particle surfaces, which suggested a balance between the oxygen-centered and the carbon-centered radicals. Radical signals on the $\mathrm{ZnO}$ and $\mathrm{NiO}$ particle surfaces resembled the previously reported profiles observed for 1,2-dichlorobenzene and monochlorobenzene on $\mathrm{Fe}_{2} \mathrm{O}_{3}$-containing particles. ${ }^{11}$ The lack of hyperfine splitting induced by a chlorine atom on the $\mathrm{ZnO}$ and $\mathrm{NiO}$ particle surfaces may result from formation of hypochlorite species, which are known to be strong oxidants and chlorinating agents. ${ }^{3,11,35}$ These hypochlorite species then contributed to decomposition of the adsorbed radical species, which meant they could not be measured.

Chlorinated radicals were only observed on $\mathrm{CuO}$ in this study, compared to that observed on other metal oxides during the thermal processes $(298-573 \mathrm{~K})$. Oxygen-carbon coupling of organic free radicals, such as trichlorophenol radicals, has been identified as the dominant formation pathway for dioxins during thermal processes. ${ }^{4}$ This pathway could explain the promotion of dioxin formation by $\mathrm{CuO}$. This result is in accordance with studies on metal oxide catalytic pathways, which have shown that $\mathrm{CuO}$ mainly promotes the chlorination of aliphatic intermediates, whereas $\mathrm{Al}_{2} \mathrm{O}_{3}$ selectively catalyzes the formation of nonchlorinated aromatics. ${ }^{36}$ Although different kinds of EPFRs formed, the varied catalytic abilities of metal oxides were reflected in the concentrations of EPRs formed on the surfaces of the metal oxide particles. The catalytic abilities of the metal oxides for EPFR formation were in the order $\mathrm{Al}_{2} \mathrm{O}_{3}>\mathrm{ZnO}>$ $\mathrm{CuO}>\mathrm{NiO}$ (Figure 2). The concentrations of EPFRs formed

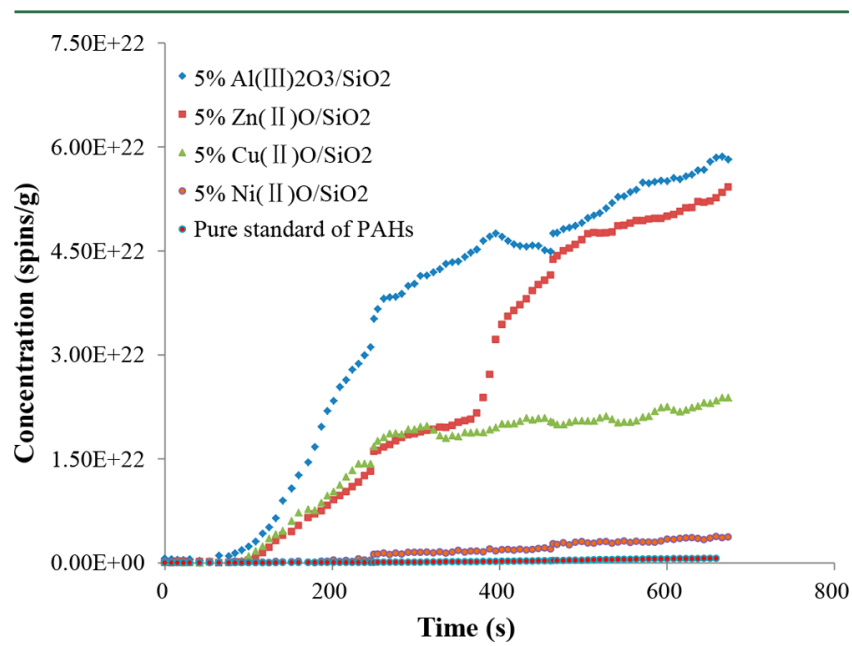

Figure 2. Concentrations of radicals formed from 2,4-dichloro-1naphthol on the surfaces of different metal oxides during thermal processes at temperatures ranging from 298 to $573 \mathrm{~K}$.

under catalysis of $\mathrm{Al}_{2} \mathrm{O}_{3}$ and $\mathrm{ZnO}$ were about twice that formed with $\mathrm{CuO}$ and 20 times that formed with $\mathrm{NiO}$. The abilities of the metal oxides to promote EPFR formation were in accordance with the oxidizing strengths of the corresponding metal cations, according to their order in the periodic table. The position of a metallic element in the periodic table is determined by its 

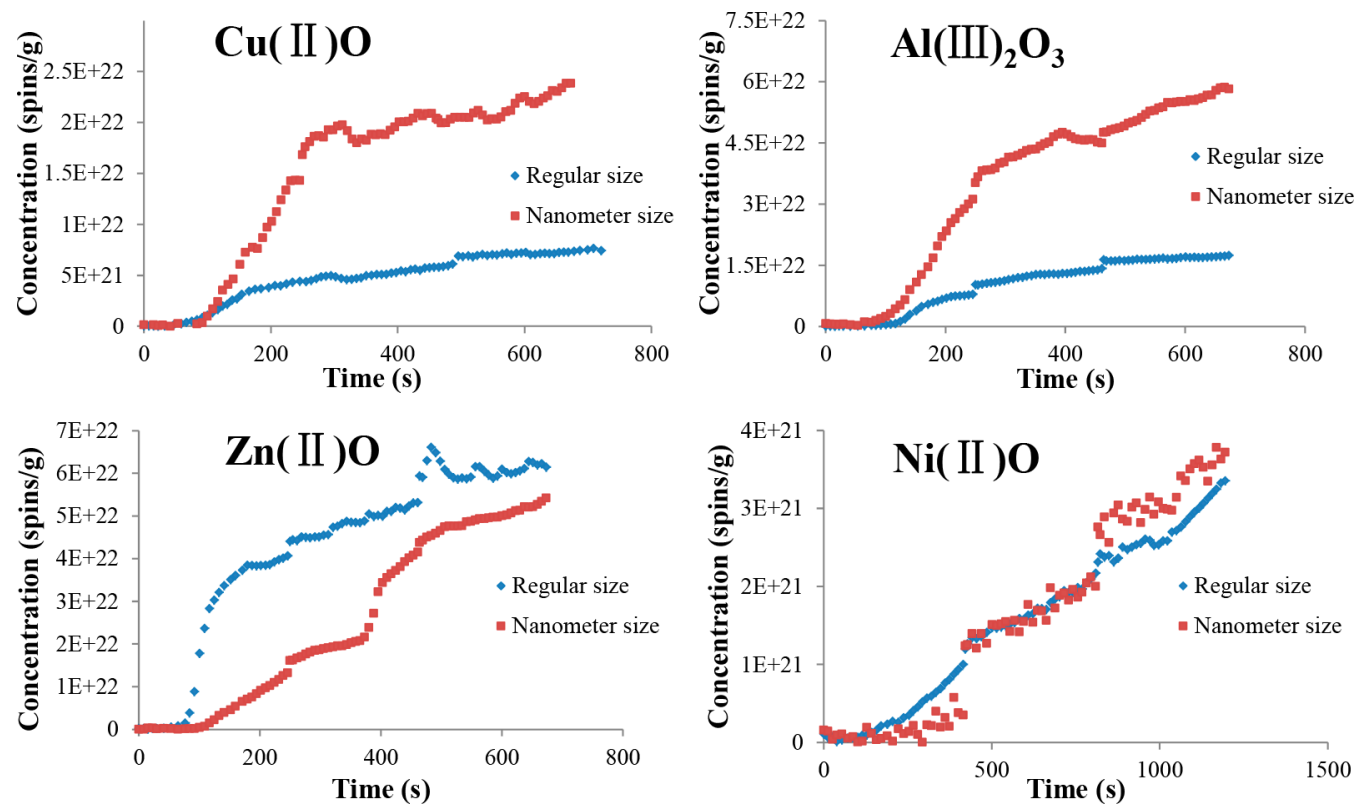

Figure 3. Concentrations of environmentally persistent free radicals produced under catalysis by micrometer-sized ( $\varnothing 5 \mu \mathrm{m})$ and nanometer-sized ( $\varnothing 30$ nm) metal oxides.

electron shell structure, and $\mathrm{Al}(\mathrm{III})$ and $\mathrm{Zn}(\mathrm{II})$ can more easily gain electrons from the adsorbates than $\mathrm{Cu}(\mathrm{II})$ and $\mathrm{Ni}(\mathrm{II})$. Therefore, the results further verified the proposed mechanism of EPFR formation by metal oxide catalysis, with electron transfer from the aromatic ring to the metal oxide as the principle step.

The decay study showed the radicals on the surfaces of $\mathrm{Al}_{2} \mathrm{O}_{3}$, $\mathrm{ZnO}, \mathrm{CuO}$, and $\mathrm{NiO}$ had long half-lives of $108,68,81$, and 86 days, respectively. Even though decay of the EPFRs produced by catalysis with the metal oxide $/ \mathrm{SiO}_{2}$ particles exhibited relatively good exponential fits in the first 60 days, the half-lives at $>60$ days were evaluated in the later days (Figure S5), which could be caused by the contribution of secondary radicals. ${ }^{11}$ The results indicated that EPFRs produced from the reactions of the PAH derivative on the surface of the metal oxide-containing particles were stable and did not react rapidly in the atmosphere. However, EPFRs will participate in atmospheric reactions, producing secondary radicals. In addition, $\mathrm{Al}_{2} \mathrm{O}_{3}$ particles are a potential source of EPFR-containing particles and should be considered because of their superior catalytic ability and stabilizing effect on EPFRs.

Effect of the Size of the Metal Oxide-Containing $\mathrm{SiO}_{2}$ Particle on EPFR Formation. The effects of metal oxide particle size on EPFR formation were evaluated in this study. The catalytic abilities of the metal oxide $\left(\mathrm{Al}_{2} \mathrm{O}_{3}, \mathrm{CuO}\right.$, and $\left.\mathrm{NiO}\right)$ nanoparticles were all higher than those of micrometer-sized particles (Figure 3). This manifested as radical concentrations on the surfaces of the $\mathrm{Al}_{2} \mathrm{O}_{3} / \mathrm{SiO}_{2}$ and $\mathrm{CuO} / \mathrm{SiO}_{2}$ nanoparticles that were four times those on the micrometer-sized particles. For the $\mathrm{ZnO} / \mathrm{SiO}_{2}$ particles at $573 \mathrm{~K}$, the concentration of EPFRs formed on the surface of the micrometer-sized particles was about 1.13 times that on the surface of the nanoparticles. However, the EPFR concentration obtained with the nanoparticles was increasing at this point, whereas that for the micrometer-sized particles was stable. This trend for the $\mathrm{ZnO} /$ $\mathrm{SiO}_{2}$ particles (Figure 3) indicates that the metal oxide nanoparticles will have stronger catalytic abilities than the micrometer-sized particles during the actual thermal process with longer heating times and higher heating temperatures.

In addition, in consideration of the large annual output of $\mathrm{SiO}_{2}$ nanoparticles, the size effects of both the $\mathrm{SiO}_{2}$ substrate and the metal oxide should be identified. Consequently, $\mathrm{SiO}_{2}$ and $\mathrm{CuO}$ particles of different sizes were mixed, and the EPFR concentrations produced under their catalysis were evaluated. The results showed that the dynamic changes in the EPFR concentrations were highest when $\mathrm{CuO}$ nanoparticles were combined with $\mathrm{SiO}_{2}$ nanoparticles (Figure S6). Slight increases in the EPFR concentrations were observed with $\mathrm{SiO}_{2}$ nanoparticles (lines A versus B and C versus E in Figure S6), which could be attributed to better dispersion of the nanoparticles because of their larger surface areas and prevention of radical coupling. The $\mathrm{CuO}$ nanoparticles $(\varnothing 30 \mathrm{~nm})$ greatly increased the EPFR concentrations compared with the micrometer-sized $\mathrm{CuO}(ø 5 \mu \mathrm{m})$ (lines B versus $\mathrm{C}$ and D versus $\mathrm{E}$ in Figure S6), which indicated particle size played an important role in EPFR formation. Reportedly, metal oxide nanoparticles always contain $\mathrm{O}^{--}$, which can react with hydrocarbons as shown below. ${ }^{37,38}$

$$
\mathrm{O}^{-}+\mathrm{RH} \rightarrow \mathrm{R}+\mathrm{OH}^{-}
$$

Therefore, the metal oxide nanoparticles containing $\mathrm{O}^{\bullet-}$ can greatly improve the reactivity for $\mathrm{H}$ abstraction, which has been identified as the first step in formation of EPFRs and other organic pollutants. ${ }^{2,4}$ This function of $\mathrm{O}^{\bullet-}$ combined with the large specific surface areas of the metal oxide nanoparticles can result in elevated EPFR concentrations. Large quantities of nanoparticles are produced annually, and nanoparticles can also form through condensation of materials after filtration in the thermal process, and these are then emitted into the atmosphere. $^{18}$ The $\mathrm{O}^{-}$contained in these particles could react with organic pollutants in the atmosphere and contribute to the formation of EPFRs, even without heating. This speculation supplements our previous study on the sources of EPFRs in the atmospheric PM. In that they arise not only from human activities, such as coal burning, automobile exhaust, biomass burning, and thermal processes, ${ }^{39}$ but also from the transformation of organic pollutants with catalysis by metal oxide- 

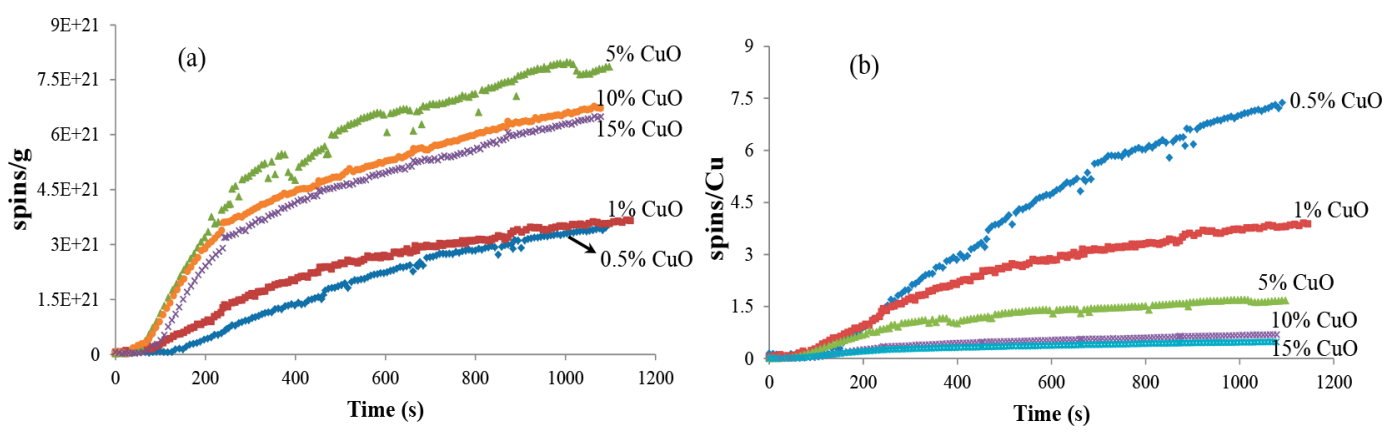

Figure 4. (a) Concentrations of environmentally persistent free radicals produced on silica particles containing different mass fractions of $\mathrm{CuO}$ during heating at temperatures from 298 to $573 \mathrm{~K}$. (b) Dependence of the environmentally persistent free radical density on the metal mass fraction during heating at temperatures from 298 to $573 \mathrm{~K}$.

containing particles, and especially metal oxide nanoparticles. The synergic toxicity of the metal oxide nanoparticles and EPFRs should be investigated further.

Effect of the Metal Oxide Concentration on EPFR Formation. Different concentrations of metal oxides may contribute to formation of metal oxide clusters with different sizes, which has been identified above as an important parameter in the catalysis of EPFR formation. Because the metals present in PM from different sources will vary greatly and this may affect the EPFR yield, it is important to evaluate the influence of the metal oxide concentration (or mass fraction) on the formation of EPFRs. In the present study, $\mathrm{CuO}$ was selected for its known redox properties. In our previous studies, we investigated the formation of EPFRs and their roles as important intermediates in dioxin formation during thermal processes. ${ }^{4,5}$ Therefore, EPFR yields were obtained using $\mathrm{SiO}_{2}$-based synthetic PM containing various mass fractions of $\mathrm{CuO}$. With the different mass fractions, the radical signals were quite similar, with $g$ factors around 2.0035 and $\Delta H_{p-p}$ values ranging from 3.4 to 4.1 . Because the copper sites are the most active in the formation of EPFRs, the radical yield should be proportional to the $\mathrm{CuO}$ mass fraction. However, this was not the case. Generally, the adsorption of 2,4-dichloro-1naphthol on $5 \% \mathrm{CuO} / \mathrm{SiO}_{2}$ resulted in the highest concentration of radicals (Figure 4a). When the $\mathrm{CuO}$ mass fraction was below $5 \%$, rapid increases in the radical concentrations occurred along with the increase in the $\mathrm{CuO}$ mass fraction (Figure 4a). However, when the $\mathrm{CuO}$ mass fraction was higher than $5 \%$, the radical yields were lower than those obtained with $<5 \% \mathrm{CuO}$. This was in contrast to what we expected. The EPFR densities obtained during the thermal processing of 2,4-dichloro-1-naphthol on various $\mathrm{CuO} / \mathrm{SiO}_{2}$ nanoparticles were calculated to evaluate the catalytic efficiency of $\mathrm{CuO}$ (Figure $4 \mathrm{~b}$ ). With $0.5 \% \mathrm{CuO}$, about nine radicals formed for every copper atom in the samples at 573 $\mathrm{K}$. It should be noted that not all of the radicals we detected were produced by $\mathrm{CuO}$ catalysis. Hydrogen abstraction can also occur during thermal processes without metal oxide particles. ${ }^{4}$ However, from the downtrend observed for the radical concentrations under catalysis by $0.5 \%, 1 \%$, and $5 \% \mathrm{CuO} / \mathrm{SiO}_{2}$ (Figure 4b), we can assume complete saturation of the surface sites with adsorbates with a $\mathrm{CuO}$ mass fraction below $5 \%$. If the $\mathrm{CuO}$ mass fraction was higher than $5 \%$, three-dimensional growth of the $\mathrm{CuO}$ clusters occurred and trapped the copper atoms inside the clusters, which resulted in formation of one radical for every two copper atoms. ${ }^{15}$ Therefore, $\mathrm{CuO}$ cluster formation when the mass fraction was higher than $5 \%$ would reduce its interaction with precursors and contribute to the radical concentration decrease. Even though $5 \%$ is a higher mass fraction than that reported for copper in PM generated during thermal processes, this mass fraction is appropriate for ultrafine $\mathrm{PM}$ in the atmosphere, where the concentration of metal increases with decreasing particle size. ${ }^{40}$ Therefore, EPFR formation on the ultrafine particles should be considered because of the appropriate mass fraction of metal oxide and ability of ultrafine particles containing nanosized ones to promote EPFR formation. Overall, the results in this study indicated that EPFR formation was dependent on the mass fraction of $\mathrm{CuO}$. Therefore, the metal oxide mass fractions in different matrices, such as PM and fly ash, may contribute to the different characteristics or yields of EPFRs.

In summary, the catalytic effects of different metal oxides on the formation of EPFR species and their lifetimes and yields were assessed and found to be in accordance with the oxidation ability of the corresponding metal atom. The catalytic abilities of metal oxides were in the order $\mathrm{Al}_{2} \mathrm{O}_{3}>\mathrm{ZnO}>\mathrm{CuO}>\mathrm{NiO}$. Compared with $\mathrm{CuO}, \mathrm{Al}_{2} \mathrm{O}_{3}$ has not been well studied and should be a focus of research on EPFR formation in the future. Because $\mathrm{CuO}$ stabilizes chlorinated radicals, which contributes to its remarkable catalytic ability in dioxin formation, it should also be investigated further. The effects of the mass fractions and cluster sizes of metal oxides on the catalytic activity were also evaluated in this work. The surface concentrations of radicals were correlated to the mass fractions of the metal oxides. The synergic toxicity of metal oxide nanoparticles and EPFRs should be studied further because metal oxide nanoparticles could result in elevated EPFR concentrations.

\section{ASSOCIATED CONTENT}

\section{S Supporting Information}

The Supporting Information is available free of charge on the ACS Publications website at DOI: 10.1021/acs.est.7b03583.

Possible pathways for the formation of persistent free radicals from 2,4-dichloro-1-naphthol on a generic metal oxide; dynamic changes in the electron spin resonance spectra of 2,4-dichloro-1-naphthol on the surfaces of silicon dioxide-supported $\mathrm{Al}_{2} \mathrm{O}_{3}, \mathrm{ZnO}$, and $\mathrm{NiO}$ from 298 $\mathrm{K}$ to $573 \mathrm{~K}$; radical formed at the temperature of $573 \mathrm{~K}$ at different microwave attenuations; photoelectron spectra of $\mathrm{Cu}(\mathrm{II}) \mathrm{O}$ mixed with 2,4-dichloro-1-naphthol and silicon dioxide before and after the thermal process; electron paramagnetic resonance spectra of environmentally persistent free radicals under catalysis by different metal oxides, and fitting of the pseudo-firstorder rate law expression to the signal from radicals on the surfaces of $\mathrm{Al}_{2} \mathrm{O}_{3}$ particles; concentrations of radicals 
formed from 2,4-dichloro-1-naphthol on the surfaces of particles composed of silicon dioxide $\left(\mathrm{SiO}_{2}\right)$ and copper oxide $(\mathrm{CuO})$ for thermal processes at temperatures between 298 and $573 \mathrm{~K}$ (PDF)

\section{AUTHOR INFORMATION}

\section{Corresponding Author}

*E-mail: grliu@rcees.ac.cn.

\section{ORCID $\odot$}

Guorui Liu: 0000-0002-8462-6734

Minghui Zheng: 0000-0001-5270-6759

Rong Jin: 0000-0001-9677-6177

Notes

The authors declare no competing financial interest.

\section{ACKNOWLEDGMENTS}

This work was supported by the Chinese National 973 Program (Grant No. 2015CB453100), the National Natural Science Foundation of China (Grant No. 91543108), the Strategic Priority Research Program of the Chinese Academy of Sciences (Grant No. XDB14020102), and the Youth Innovation Promotion Association of the Chinese Academy of Sciences (Grant No. 2016038). We thank Jiahui Yang (engineer, Bruker Instruments) for her helpful discussion on EPR calculation theory.

\section{REFERENCES}

(1) Saravia, J.; Lee, G. I.; Lomnicki, S.; Dellinger, B.; Cormier, S. A. Particulate Matter Containing Environmentally Persistent Free Radicals and Adverse Infant Respiratory Health Effects: A Review. J. Biochem. Mol. Toxicol. 2013, 27 (1), 56-68.

(2) Dellinger, B.; Lomnicki, S.; Khachatryan, L.; Maskos, Z.; Hall, R. W.; Adounkpe, J.; McFerrin, C.; Truong, H. Formation and stabilization of persistent free radicals. Proc. Combust. Inst. 2007, 31, 521-528.

(3) Lomnicki, S.; Dellinger, B. A detailed mechanism of the surfacemediated formation of $\mathrm{PCDD} / \mathrm{F}$ from the oxidation of 2-chlorophenol on a $\mathrm{CuO} /$ silica surface. J. Phys. Chem. A 2003, 107 (22), 4387-4395.

(4) Yang, L.; Liu, G.; Zheng, M.; Zhao, Y.; Jin, R.; Wu, X.; Xu, Y. Molecular Mechanism of Dioxin Formation from Chlorophenol based on Electron Paramagnetic Resonance Spectroscopy. Environ. Sci. Technol. 2017, 51 (9), 4999-5007.

(5) Lomnicki, S.; Truong, H.; Vejerano, E.; Dellinger, B. Copper oxidebased model of persistent free radical formation on combustion-derived particulate matter. Environ. Sci. Technol. 2008, 42 (13), 4982-8.

(6) Lubick, N. Persistent free radicals: discovery and mechanisms for health impacts. Environ. Sci. Technol. 2008, 42 (22), 8178-8178.

(7) Mahne, S.; Chuang, G. C.; Pankey, E.; Kiruri, L.; Kadowitz, P. J.; Dellinger, B.; Varner, K. J. Environmentally persistent free radicals decrease cardiac function and increase pulmonary artery pressure. American Journal of Physiology-heart and Circulatory Physiology 2012, 303 (9), H1135-H1142.

(8) Khachatryan, L.; Dellinger, B. Environmentally persistent free radicals (EPFRs)-2. Are free hydroxyl radicals generated in aqueous solutions? Environ. Sci. Technol. 2011, 45 (21), 9232-9.

(9) Balakrishna, S.; Lomnicki, S.; McAvey, K. M.; Cole, R. B.; Dellinger, B.; Cormier, S. A. Environmentally persistent free radicals amplify ultrafine particle mediated cellular oxidative stress and cytotoxicity. Part. Fibre Toxicol. 2009, 6, 11.

(10) Vejerano, E.; Lomnicki, S. M.; Dellinger, B. Formation and stabilization of combustion-generated, environmentally persistent radicals on $\mathrm{Ni}(\mathrm{II}) \mathrm{O}$ supported on a silica surface. Environ. Sci. Technol. 2012, 46 (17), 9406-11.

(11) Vejerano, E.; Lomnicki, S.; Dellinger, B. Formation and Stabilization of Combustion-Generated Environmentally Persistent
Free Radicals on an $\mathrm{Fe}(\mathrm{III})(2) \mathrm{O}-3 /$ Silica Surface. Environ. Sci. Technol. 2011, 45 (2), 589-594.

(12) Mei, W.; Guorui, L.; Xiaoxu, J.; Wenbin, L.; Li, L.; Sumei, L.; Minghui, Z.; Jiayu, Z. Brominated dioxin and furan stack gas emissions during different stages of the secondary copper smelting process. Atmos. Pollut. Res. 2015, 6 (3), 464-468.

(13) Liu, G.; Lv, P.; Jiang, X.; Nie, Z.; Zheng, M. Identifying iron foundries as a new source of unintentional polychlorinated naphthalenes and characterizing their emission profiles. Environ. Sci. Technol. 2014, 48 (22), 13165-72.

(14) Dreher, K. L.; Jaskot, R. H. Soluble Transition Metals Mediate Residual Oil Fly Ash Induced Acute Lung Injury. J. Toxicol. Environ. Health 1997, 50 (3), 285-305.

(15) Kiruri, L. W.; Khachatryan, L.; Dellinger, B.; Lomnicki, S. Effect of copper oxide concentration on the formation and persistency of environmentally persistent free radicals (EPFRs) in particulates. Environ. Sci. Technol. 2014, 48 (4), 2212-7.

(16) Zhou, X. C.; Xu, W. L.; Liu, G. K.; Panda, D.; Chen, P. SizeDependent Catalytic Activity and Dynamics of Gold Nanoparticles at the Single-Molecule Level. J. Am. Chem. Soc. 2010, 132 (1), 138-146.

(17) Liu, C.; Shi, S.; Weschler, C.; Zhao, B.; Zhang, Y. Analysis of the Dynamic Interaction Between SVOCs and Airborne Particles. Aerosol Sci. Technol. 2013, 47 (2), 125-136.

(18) Wiesner, M. R.; Plata, D. L. Environmental, health and safety issues: Incinerator filters nanoparticles. Nat. Nanotechnol. 2012, 7 (8), $487-8$.

(19) Tolaymat, T.; El Badawy, A.; Genaidy, A.; Abdelraheem, W.; Sequeira, R. Analysis of metallic and metal oxide nanomaterial environmental emissions. J. Cleaner Prod. 2017, 143, 401-412.

(20) Stoeger, T.; Takenaka, S.; Frankenberger, B.; Ritter, B.; Karg, E.; Maier, K.; Schulz, H.; Schmid, O. Deducing in Vivo Toxicity of Combustion-Derived Nanoparticles from a Cell-Free Oxidative Potency Assay and Metabolic Activation of Organic Compounds. Environ. Health Perspect. 2009, 117 (1), 54-60.

(21) Wang, Y.; Ding, L.; Yao, C.; Li, C.; Xing, X.; Huang, Y.; Gu, T.; $\mathrm{Wu}, \mathrm{M}$. Toxic effects of metal oxide nanoparticles and their underlying mechanisms. Science China Materials 2017, 60 (2), 93-108.

(22) Preining, O. The physical nature of very, very small particles and its impact on their behaviour. J. Aerosol Sci. 1998, 29 (5-6), 481-495.

(23) Bochenkov, V. E.; Sergeev, G. B. Adsorption, catalysis, and reactions on the surfaces of metal nano-oxides. Catalysis in Industry 2010, 2 (1), 1-10.

(24) Sun, J.; Wang, S.; Zhao, D.; Hun, F. H.; Weng, L.; Liu, H. Cytotoxicity, permeability, and inflammation of metal oxide nanoparticles in human cardiac microvascular endothelial cells: cytotoxicity, permeability, and inflammation of metal oxide nanoparticles. Cell Biol. Toxicol. 2011, 27 (5), 333-42.

(25) Cetta, F.; Dhamo, A.; Moltoni, L.; Bolzacchini, E. Adverse health effects from combustion-derived nanoparticles: the relative role of intrinsic particle toxicity and host response. Environ. Health Perspect. 2009, 117 (5), A190.

(26) Lin, X.; Zuo, Y. Y.; Gu, N. Shape affects the interactions of nanoparticles with pulmonary surfactant. Science China Materials 2015, 58 (1), 28-37.

(27) Colvin, V. L. The potential environmental impact of engineered nanomaterials. Nat. Biotechnol. 2003, 21 (10), 1166-70.

(28) Hoet, P. H. M.; Nemmar, A.; Nemery, B. Health impact of nanomaterials? Nat. Biotechnol. 2004, 22, 19.

(29) Nwosu, U. G.; Roy, A.; Dela Cruz, A. L. N.; Dellinger, B.; Cook, R. Formation of environmentally persistent free radical (EPFR) in iron(III) cation-exchanged smectite clay. Environmental science. Processes \& impacts 2016, 18 (1), 42-50.

(30) Jia, H.; Zhao, J.; Li, L.; Li, X.; Wang, C. Transformation of polycyclic aromatic hydrocarbons (PAHs) on $\mathrm{Fe}(\mathrm{III})$-modified clay minerals: Role of molecular chemistry and clay surface properties. Appl. Catal., B 2014, 154-155, 238-245.

(31) Jia, H.; Nulaji, G.; Gao, H.; Wang, F.; Zhu, Y.; Wang, C. Formation and Stabilization of Environmentally Persistent Free Radicals 
Induced by the Interaction of Anthracene with $\mathrm{Fe}(\mathrm{III})$-Modified Clays. Environ. Sci. Technol. 2016, 50 (12), 6310-9.

(32) Qu, X.; Wang, X.; Zhu, D. The partitioning of PAHs to egg phospholipids facilitated by copper and proton binding via cation-pi interactions. Environ. Sci. Technol. 2007, 41 (24), 8321-7.

(33) Nwosu, U. G.; Khachatryan, L.; Youm, S. G.; Roy, A.; Dela Cruz, A. L. N.; Nesterov, E. E.; Dellinger, B.; Cook, R. L. Model system study of environmentally persistent free radicals formation in a semiconducting polymer modified copper clay system at ambient temperature. RSC Adv. 2016, 6 (49), 43453-43462.

(34) Patterson, M. C.; Keilbart, N. D.; Kiruri, L. W.; Thibodeaux, C. A.; Lomnicki, S.; Kurtz, R. L.; Poliakoff, E. D.; Dellinger, B.; Sprunger, P. T. EPFR Formation from Phenol adsorption on $\mathrm{Al} 2 \mathrm{O}$ and TiO: EPR and EELS studies. Chem. Phys. 2013, 422, 277-282.

(35) Farquar, G. R.; Alderman, S. L.; Poliakoff, E. D.; Dellinger, B. Xray spectroscopic studies of the high temperature reduction of $\mathrm{Cu}(\mathrm{II}) \mathrm{O}$ by 2 -chlorophenol on a simulated fly ash surface. Environ. Sci. Technol. 2003, 37 (5), 931-5.

(36) Froese, K. L.; Hutzinger, O. Mechanisms of the formation of polychlorinated benzenes and phenols by heterogeneous reactions of C2 aliphatics. Environ. Sci. Technol. 1997, 31 (2), 542-547.

(37) Ding, X. L.; Wu, X. N.; Zhao, Y. X.; He, S. G. C-H bond activation by oxygen-centered radicals over atomic clusters. Acc. Chem. Res. 2012, 45 (3), 382-90.

(38) Zhang, M. Q.; Zhao, Y. X.; Liu, Q. Y.; Li, X. N.; He, S. G. Does Each Atom Count in the Reactivity of Vanadia Nanoclusters? J. Am. Chem. Soc. 2017, 139 (1), 342-347.

(39) Yang, L. L.; Liu, G.; Zheng, M.; Jin, R.; Zhu, Q.; Zhao, Y.; Wu, X.; $\mathrm{Xu}, \mathrm{Y}$. Highly Elevated Levels and Particle-Size Distributions of Environmentally Persistent Free Radicals in Haze-Associated Atmosphere. Environ. Sci. Technol. 2017, 51, 7936-7944.

(40) Allouis, C.; Beretta, F.; D’Alessio, A. Structure of inorganic and carbonaceous particles emitted from heavy oil combustion. Chemosphere 2003, 51 (10), 1091-1096. 